\title{
Promoting Interprofessional Collaboration in Biomedical Research
}

\author{
Patricia A Findley* \\ School of Social Work, Rutgers University, The State University of New Jersey, USA
}

*Corresponding author: Patricia A Findley, School of Social Work, Rutgers University, The State University of New Jersey, 120 Albany Street, New Brunswick, New Jersey, USA.

To Cite This Article: Patricia A Findley. Promoting Interprofessional Collaboration in Biomedical Research. Am J Biomed Sci \& Res. 2019 - 4(5). AJBSR.MS.ID.000821. DOI: 10.34297/AJBSR.2019.04.000821

Received: August 07, 2019 | Published: August 13, 2019

\section{Introduction}

Health professionals working in silos or in ways that are not collaborative is no longer sustainable for healthcare [1]. For over 20 years national and international professional organizations have sought the reform necessary to educate health professional student in an interprofessional (i.e. interdisciplinary) manner. The impetus for this reform came in 2000 when the Institute of Medicine (IOM) released the report "To Err is Human: Building a Safer Health System"[1]. This influential document outlined the deficits in health care quality and safety in the United States and how the development of interdisciplinary teams could be solution. In 2003, the IOM restated the urgency to promote interprofessional education (IPE) in the curriculum for all health care professions to increase health care quality [2] . The World Health Organization's (WHO) 2010 Framework for Action on Interprofessional Education and Collaborative Practice suggested that IPE training would seek to have trainees learn "with, from, and about" one another's disciplines, training, and scopes of practice as a way to increase health care quality and safety [3]. In 2003, the IOM reiterated the link between interdisciplinary teamwork and health care quality. In 2011, the Interprofessional Education Collaborative (IPEC) published Core Competencies for Interprofessional Collaborative Practice [4] and an update was provided in 2016 with the same title [5].

The IPEC set forth 4 Core Competencies that are based on the following principles: patient and family (hereafter termed "patientcentered"); community and population oriented, relationship focused; process oriented; linked to learning activities; educational strategies, and behavioral assessments that are developmentally appropriate for the learner; able to be integrated across the learning continuum; sensitive to systems context and applicable across practice settings; applicable across professions; stated in language common and meaningful across professions; and outcome driven $[5]$.
The following are the 4 Core Competencies:

Competency 1: Work with individuals of other professions to maintain a climate of mutual respect and shared values. (Values/ Ethics for Interprofessional Practice)

Competency 2: Use the knowledge of one's own role and those of other professions to appropriately assess and address the health care needs of patients and to promote and advance the health of populations. (Roles/Responsibilities)

Competency 3: Communicate with patients, families, communities, and professionals in health and other fields in a responsive and responsible manner that supports a team approach to the promotion and maintenance of health and the prevention and treatment of disease. (Interprofessional Communication)

Competency 4: Apply relationship-building values and the principles of team dynamics to perform effectively in different team roles to plan, deliver, and evaluate patient/population centered care and population health programs and policies that are safe, timely, efficient, effective, and equitable. (Teams and Teamwork)

The value of IPE leading towards interprofessional collaborative practice (IPCP) in health care has been seen invaluable in achieving the Triple Aim of today's health care-improved health of the population, improved patient care experience, and improved affordability of care [6]. Indeed, IPCP has been cited as increasing outcomes in a variety of health care areas including transforming heart failure care [7], the perceptions of patients in intensive care units [8,9], and even at the end of life [10].

A critical value of the IPEC competencies is that they have been supported by national professional organizations that oversee accreditation 15 disciplines including the 2011 founding members the American Association of Colleges of Nursing (AACN), Association of American Medical Colleges (AAMC), American 
Association of Colleges of Pharmacies (AACP), American Dental Association (ADEA), Association of Schools and Programs of Public Health (ASPPH), and the American Association of Colleges of Osteopathic Medicine (AACOM). In 2016, physical therapy, social work, podiatric medicine, occupational therapy, complementary and alternative health practitioners, veterinary medicine, physician assistants, psychologists, speech-language pathologists, optometrists, and allied health professions (which includes biomedical scientists) joined as institutional members to promote IPE and IPCP to promote patient outcomes.

The benefit of practicing collaborative care can be evidenced in our research by including authors of varying disciplines. Clinicians and researchers trained prior to the introduction of IPE and IPCP at a loss by not being able to capitalize on the richness IPCP can bring, nor should they force the IPE and IPCP training out of a newly trained professional in favor of more traditional siloed ways of thinking. The integration of IPCP in research can add depth and breadth to research. For example, the concept of social determinants of health widely discussed in the nursing and social work literature can bring a new dimension to dental school curriculum [11]. Or the collaborative contributions of a pharmacist, a physician, an economist, and social worker to address the role of non-adherence to statins and antihypertensives and hospitalizations among elderly Medicare beneficiaries with incident cancer [12]. Understanding the scopes of practice of various disciplines, allows us as researchers to think outside of our own to enrich the work that we do. One of the benefits of a multidisciplinary/interdisciplinary team is that we bring different perspectives so we can learn with each other, from each other, and about each other as we role model for the current generation about professional collaboration. Competency 4 specifically calls upon us to work collaboratively as team members to evaluate care and to assess if programs are safe, timely, efficient, effective, and equitable. The only way to demonstrate a responsible research agenda to address Competency 4 is to conduct it in a collaborative manner that includes an interdisciplinary team to address the complex and interrelated research questions it prompts. The health care field is demanding IPCP, we need to respond to that call to action with responsible research.

\section{References}

1. Donaldson MS, Corrigan JM, Kohn LT (2000) To err is human: building a safer health system. National Academies Press, Washington, USA.

2. Page A (2004) Keeping patients safe: Transforming the work environment of nurses. National Academies Press, Washington, USA.

3. Gilbert JH, Yan J, Hoffman SJ (2010) A WHO report: framework for action on interprofessional education and collaborative practice. Journal of Allied Health 39(3): 196-197.

4. (2011) Interprofessional Education Collaborative Expert Panel. Core competencies for interprofessional collaborative practice: Report of an expert panel. Interprofessional Education Collaborative, Washington, USA.

5. (2016) Collaborative IE. Core competencies for interprofessional collaborative practice: 2016 update. Interprofessional Education Collaborative, Washington, US.

6. Berwick DM, Nolan TW, Whittington J (2008) The triple aim: care, health, and cost. Health Aff 27(3): 759-769.

7. Zierler BK, Abu-Rish Blakeney E, O’Brien KD, Teams IHF (2018) An interprofessional collaborative practice approach to transform heart failure care: An overview. J Interprof Care 32(3): 378-381.

8. Chen DW, Gerolamo AM, Harmon E, Bistline A, Sicks S, et al. (2018) Interprofessional collaborative practice in the medical intensive care unit: A survey of caregivers' perspectives. J Gen Intern Med 33(10): 1708-1713.

9. Song B, Zhang Y, Wang Y, An X (2018) Intensive patients' care program ameliorates anxiety and depression, and sustained anxiety correlates with worse overall survival in renal cell carcinoma patients underwent radical nephrectomy. Translational Cancer Research 7(6): 1601-1613.

10. Albers A, Bonsignore L, Webb M (2018) A Team-Based Approach to Delivering Person-Centered Care at the End of Life. N C Med J 79(4): 256258.

11. Sabato E, Owens J, Mauro AM, Findley P, Lamba S, Fenesy K (2018) Integrating social determinants of health into dental curricula: an interprofessional approach. J Dent Educ 82(3): 237-245.

12. Chopra I, Dwibedi N, Mattes MD, Tan X, Findley P, et al. (2017) Nonadherence to statins and Antihypertensives and hospitalizations among elderly Medicare beneficiaries with incident cancer. Journal of the National Comprehensive Cancer Network. 15(11): 1351-1360. 